Revista de la red interuniversitaria de estudios sobre las literaturas rioplatenses contemporáneas en Francia

$23 \mid 2021$

La vereda de enfrente. Cruces entre las literaturas argentina y chilena del siglo XX

\title{
Los textos documentales: entre testimonio y grabación
}

Les textes documentaires: entre témoignage et enregistrement

Documentary texts: between testimony and recording

Frédéric Pouillaude

Traductor. Inés Da Graça Gaspar

\section{(2) OpenEdition}

Journals

Edición electrónica

URL: https://journals.openedition.org/lirico/11809

DOI: $10.4000 /$ lirico. 11809

ISSN: 2262-8339

Editor

Réseau interuniversitaire d'étude des littératures contemporaines du Río de la Plata

Referencia electrónica

Frédéric Pouillaude, «Los textos documentales: entre testimonio y grabación», Cuadernos LIRICO [En línea], 23 | 2021, Publicado el 09 diciembre 2021, consultado el 07 enero 2022. URL: http:// journals.openedition.org/lirico/11809; DOI: https://doi.org/10.4000/lirico.11809

Este documento fue generado automáticamente el 7 enero 2022.

\section{cc)}

Cuadernos LIRICO está distribuido bajo una Licencia Creative Commons Atribución-NoComercial-

SinDerivar 4.0 Internacional. 


\title{
Los textos documentales: entre testimonio y grabación
}

\author{
Les textes documentaires: entre témoignage et enregistrement \\ Documentary texts: between testimony and recording
}

Frédéric Pouillaude

Tradución : Inés Da Graça Gaspar

\section{NOTA DEL EDITOR}

En nombre de Cuadernos LIRICO, agradecemos el acuerdo del autor para traducir este fragmento del capítulo VI de su libro Représentations factuelles. Arts et pratiques documentaires, Paris, Editions du Cerf, 2020.

Aclaración: cuando el autor remite a números de página de la edición francesa de su libro, se ha optado por indicar los títulos de los capítulos a los que hace referencia.

1 Dentro del campo literario, el adjetivo "documental" no parece designar una forma ni un género claramente establecidos. Desde los análisis de Genette en Ficción y dicción, y según una generalización algo abusiva, fue la apelación "literaturas factuales" la que prevaleció en los estudios literarios para designar el conjunto de las "literaturas no

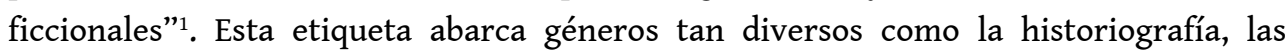
memorias, las biografías, los relatos de viaje, las autobiografías, el diario, el testimonio, la investigación periodística, el reportaje, el ensayo... (Jeannelle 2007 Web). La solidez propia de estos géneros, su largo arraigo histórico y la forma en que parecen cubrir la totalidad del territorio "no ficcional" no dejaron ningún espacio para una hipotética categoría llamada "literatura documental".

2 Sin embargo, debido a la inadecuación de esos géneros para caracterizar ciertas prácticas contemporáneas, debido también a la envergadura y al poder de atracción de la denominación "documental" que, desde sus usos fotográficos y cinematográficos, podría también pasar por categoría genérica alternativa en literatura, debido, en fin, a 
la heterogeneidad profunda de los géneros vinculados por una noción de factualidad básicamente definida como no ficcionalidad, por todas esas razones, entonces, el término "documental" empieza claramente a abrirse paso entre los estudios literarios. La publicación en 2012 de un número de la revista Littérature, titulado "Usages du document en littérature", es un buen indicio de este interés relativamente nuevo (Bloomfield y Zenetti 2012). Me detendré, en particular, en dos de sus artículos: "Un réalisme contemporain: les narrations documentaires" de Lionel Ruffel, y "Prélèvement/déplacement: le document au lieu de l'œuvre" de Marie-Jeanne Zenetti (Ruffel 2012 y Zenetti 2012). En ellos, se divisan dos direcciones : por un lado, la reunión propuesta por Lionel Ruffel bajo una etiqueta a la vez genérica e histórico-artística -las "narrativas/narraciones documentales" como manifestación de un "realismo contemporáneo"- de un conjunto de obras a medio camino entre la investigación periodística y el relato literario (Emmanuel Carrère, Jean Rolin, Jean Hatzfeld, pero también Svetlana Alexievitch o Roberto Saviano); por otro lado, el enfoque de MarieJeanne Zenetti, sobre el lugar y los usos del documento en el texto literario contemporáneo que tiende, al contrario, a dejar atrás (incluso a excluir) la dimensión narrativa en beneficio de la extracción, inserción y composición textual de fragmentos documentales más o menos brutos. Este análisis fue prolongado en un trabajo general publicado en 2014 en el cual se proporcionó un marco teórico más amplio basado en la noción de grabación literaria y desembocó en la categoría genérica de "factografías" (Zenetti 2014). Así, en uno de los casos, es la presencia textual del documento la que prima sobre el relato (Zenetti), en el otro, es el modelo implícito del documental cinematográfico el que tiende a convertir el relato de investigación en paradigma, haciendo que la presentación de documentos se vuelva accesoria (Ruffel). Me parece que ambas perspectivas, indudablemente complementarias, se deben integrar dentro de un modelo teórico más inclusivo. Por una parte, una obra documental no tiene necesariamente que presentar, ni siquiera usar, documentos para ser calificada de documental: sólo es necesario y basta con que ella, por su propio acto, los produzca (ver capítulo "Documental, documento, representación" del presente trabajo). Por otra parte, el panorama que esbozan estas dos posturas (por un lado, los relatos largos de las "narraciones documentales" de Ruffel, por otro, las breves transcripciones y notaciones de hechos de Zenetti) se encuentra más o menos abarcado por la dualidad que propongo entre el testimonio y la grabación. De hecho, esta dualidad vuelve a manifestarse dentro de cada postura según una tensión algo inestable. El corpus presentado por Ruffel, que podría caer bajo la categoría general de testimonio literario, incluye en realidad recopilaciones de palabras grabadas y transcritas (las recopilaciones de testimonios "en segundo grado" de Jean Hatzfeld y Svetlana Alexievitch), en las cuales la continuidad del relato y de la voz narrativa se encuentran dispersos en una multiplicidad de voces y microrrelatos. En lo que se refiere a Zenetti, ella organiza su corpus en torno a dos grandes categorías: las transcripciones -"retazos de enunciados previamente escuchados o leídos antes de ser copiados" (35)- y las notaciones -"formulación y puesta por escrito de hechos observables (pequeñas escenas, descripciones breves)"(35)-. Sin embargo, si las transcripciones atañen indiscutiblemente a la grabación, el caso de las notaciones, por muy impersonales y factuales que parezcan, me parece ubicarse más bien del lado del testimonio, ya que presuponen la presencia de un sujeto enunciador, claramente identificado con el autor, que tiene (o tuvo) la experiencia de lo que escribe. Partiendo de una acepción algo formal y general de la noción de testimonio, hay que admitir entonces, por ejemplo, 
que Perec, en Tentativa de agotar un lugar parisino, no hace, en ciertos aspectos, sino dar testimonio de lo que ve.

El caso es que, narrativa o no-narrativa, basada o no en la presencia textual de documentos, la idea de una "literatura documental" parece abrirse paso dentro de los estudios literarios francófonos. En realidad, puede que este surgimiento sea sólo un regreso o un redescubrimiento. En los años setenta, la noción fue ampliamente utilizada dentro del campo anglófono para caracterizar la literatura estadounidense de los años treinta. Aquí, hace falta recordar los trabajos de William Stott quien, bajo el título "The Documentary Nonfiction of the Thirties" dedicaba a la literatura una parte entera de su libro Documentary Expression and Thirties America (141-257). Stott, detallaba entonces la noción de "escritura documental" (document writing) de la siguiente manera:

Cuando hablamos de escritura documental, nos referimos a tres cosas: una escritura basada en documentos, o que los incluye; una escritura que graba la experiencia de las personas ordinarias, a menudo con sus propias palabras; o un reportaje de primera mano que intenta transmitir una impresión de realidad conjuntamente con los hechos (143) ${ }^{2}$.

Este esbozo de tipología (el reportaje de primera mano, la grabación de palabras y la incorporación de documentos), coincide en muchos aspectos con el que propondré más adelante, basándome entonces en la división tripartita del testimonio, la grabación y el documento. Me alejaré, sin embargo, de Stott, quien por razones aparentemente vinculadas al carácter históricamente determinado de su objeto (los Estados-Unidos de los años 1930) aplica en la selección de su corpus un filtro que me parece a la vez demasiado amplio y demasiado limitado. Demasiado limitado en el sentido de que los objetos textuales tratados por Stott manifiestan una unidad temática (las condiciones de vida de las clases sociales más desfavorecidas durante la Gran Depresión) que, aunque coherente con el enfoque social y cultural que defiende, parece difícil de exportar fuera del contexto estadounidense de los años 1930. Demasiado amplio, también, porque muchos de esos textos se enmarcan más netamente en el periodismo o en las ciencias sociales que en la literatura como tal, siendo la categoría anglosajona de "no-ficción" la que hace posible esta vaguedad. Sólo quería destacar aquí que la idea de literatura, o al menos la de escritura, "documental" no está del todo desprovista de antecedentes ${ }^{3}$.

5 Como ya lo mencioné, planteo la hipótesis de que la factualidad de las literaturas documentales se basa en las dos grandes categorías de operaciones ya identificadas: el testimonio y la grabación. El carácter factual puede surgir del compromiso asertivo del enunciador, estrictamente identificado con el autor, que habla en su propio nombre y da fe de la veracidad de sus enunciados (testimonio); o bien enmarcarse en el origen mismo de los enunciados, atribuidos, no a la subjetividad del autor, sino a una fuente exterior y anterior, que éste se ha limitado a grabar, transcribir o copiar (grabación y montaje de documentos). Sin embargo, en la medida en que las nociones de testimonio y grabación se pueden entender en varios sentidos, este esquema binario queda todavía por especificar y aguzar. Propongo entonces un escalonamiento en cinco categorías:

6 1- el testimonio en sentido fuerte o escritura retrospectiva. La "vida", la "Historia", los "eventos" llevaron a alguien a ser "testigo" de "algo", ya sea como víctima, actor o simple espectador. Este "algo", a menudo de orden violento o traumático (aunque no necesariamente), determina après-coup la necesidad o el deber o el anhelo de hablarlo, escribirlo, contarlo. Aquí pensamos, claro, en los diferentes relatos de sobrevivientes 
(Primo Levi, Robert Antelme, o Yolande Mukagasana ${ }^{4}$ ), en los cuales la violencia y el carácter excepcional de lo ocurrido provocan retrospectivamente la necesidad de la escritura testimonial. Sin embargo, esta estructura del testimonio no se limita a casos eminentes y extremos como ésos. Se aplica tanto a las Memorias en general como a las formas de narración ulteriores en las cuales la implicación del sujeto-autor en los hechos relatados puede parecer tenue o moderada. Es lo que sucede, por ejemplo, en De vidas ajenas de Emmanuel Carrère donde el autor, aunque tiene una posición de espectador o, al menos, de relativa exterioridad en cuanto a los hechos narrados (los fallecimientos de un niño y de una madre a los que conoció muy poco, tanto al uno como a la otra), no deja de hacer remontar su proyecto de escritura a la irrupción de esos dos eventos en su vida, una irrupción que, desde su punto de vista, precisamente lo erigió en testigo:

Cada mañana desde hace seis meses, voluntariamente, he pasado unas horas delante del ordenador para escribir sobre lo que más miedo me da en este mundo: la muerte de un hijo para sus padres, la de una mujer joven para sus hijas y su marido. La vida me ha hecho ser testigo de estas dos desgracias, una tras otra, y me ha encomendado, o al menos así lo he comprendido, dejar testimonio de ellas (2011: p. 237-238).

7 A pesar de la necesaria relación de copresencia entre el autor y los eventos relatados, el criterio que importa aquí reside entonces en el carácter posterior y secundario, por lo tanto derivado, del proyecto literario con respecto a los acontecimientos vividos. Es la experiencia la que, llevando al autor a ser testigo de algo, provoca el proyecto, y no lo contrario.

2- el testimonio en sentido débil o los relatos de investigación. Bajo esta categoría, conservamos el criterio de la copresencia entre el autor y los eventos relatados, pero eliminamos el de la anterioridad causal de la experiencia con respecto al proyecto. Aquí, es un proyecto preciso de escritura (sea o no explícitamente llamado "literario") lo que conduce al autor a cumplir tal o cual acción en el mundo, a emprender tal o cual viaje, a iniciar tal o cual encuentro. Las literaturas de investigación, de reportaje o de viaje, constituyen las formas paradigmáticas de esta estructura. La fuente epistémica de las aserciones no deja de ser la experiencia vivida, que engendra enunciados "de primera mano". Pero, en cambio, los cimientos existenciales del relato, sí, tienden a fragilizarse. Éste encara entonces la contingencia propia de cualquier proyecto (¿por qué hacer esto en vez de aquello? ¿por qué investigar sobre esto y no aquello? ¿por qué ir ahí en vez de allá?). Una contingencia cuyo "testimonio en sentido fuerte" parece estar ausente, ya que se funda sobre una experiencia determinante vivida con anterioridad.

Distinguir entre un sentido fuerte y un sentido débil del testimonio basándose únicamente en el carácter anterior o posterior de la experiencia vivida con respecto al proyecto de escritura tiene una ventaja. De esta forma se puede escalonar la noción y así evadir el doble riesgo de dilución dentro de una acepción demasiado amplia ("el testigo, es quien relata lo que ha vivido") o de reducción a una figura hiperbólica ("el testigo, es el sobreviviente"). Pero este escalonamiento funciona sin que por ello se tenga que recurrir a variables tales como la importancia relativa (histórica, política o moral) de los eventos vividos o el grado de implicación personal del sujeto en los eventos. Estas variables, claro está, hacen eco a ciertas intuiciones comunes, pero no por ello dejan de ser vagas y problemáticas. A estos criterios necesariamente imprecisos y cuestionables, se sustituye una pregunta factual simple (¿el proyecto de 
escritura es, sí o no, posterior a los eventos?), la cual, a pesar de su simplicidad permite dar cuenta, adecuadamente según mi parecer, del hecho de que Jean Rolin en La Cerca (2002) o Nicolas Bouvier en Los caminos del mundo (2001) no son exactamente "testigos" como lo son Primo Levi en Si esto es un hombre (1987) o Yolande Mukagasana en La muerte no me quiere (La mort ne veut pas de moi (1997).

3- el relato histórico o la investigación de cámara [de chambre]. A partir de diferentes fuentes documentales (explícitamente nombradas o no), un autor reproduce eventos que no pudo observar en persona. Obviamente, aquí se pierde la relación de copresencia. Sin embargo, subsiste algo, aunque sólo sea una huella, de la postura de testigo. Por una parte, la lógica del acto asertivo obliga a producir pruebas, indicios o razones de lo que se afirma. De modo que, un historiador que escribe sobre hechos remotos en el tiempo sigue dando fe por lo menos de una cosa, directa o indirectamente, que es su propia relación (necesariamente empírica) con las fuentes y los documentos sobre los cuales se basa su discurso. Esta fundamentación "testimonial" del trabajo del historiador se inserta generalmente en los márgenes en apariencia menos "subjetivos" de su texto, en las notas a pie de página, en el aparato crítico, cuya función es, claro, proporcionar un acceso objetivo a las fuentes, pero que, forzando un poco la imaginación, también se pueden interpretar como la consignación de los encuentros entre el historiador y el documento. Si algo queda aquí del testimonio, es gracias al imborrable fundamento empírico de toda aserción factual y a la continuidad conceptual entre copresencia y mediación documental: sea cual sea el grado de alejamiento del objeto, que éste haya sido transmitido "en persona" o, al contrario, reconstruido e investigado mediante largas cadenas documentales, siempre se habla partiendo de unas experiencias precisas (las del objeto o del documento). Por otra parte -aunque en realidad se trata del mismo tema abordado bajo otro prisma-, por muy lejanos que sean los eventos sobre los cuales se investiga y escribe, siempre se es testigo de por lo menos una cosa más, que son los propios procesos de investigación y escritura, los cuales pueden convertirse, de forma más o menos temporaria o pronunciada, en los objetos temáticos del discurso. Este diálogo entre lo reflexivo y lo testimonial (dar testimonio, no de eventos a los cuales, de todas formas, no hemos podido asistir, sino de la relación subjetiva que nos vincula a ellos y del proceso por el cual intentamos alcanzarlos) se reserva generalmente a los márgenes en apariencia menos "objetivos" del discurso académico, a los prefacios, prólogos, conclusiones o epílogos que, a lo largo de unas páginas, sueltan las riendas de la subjetividad historiadora. Una vez transferido al campo literario, este diálogo puede convertirse en el propio núcleo del trabajo y de la escritura, tal y como lo demuestran obras tan diferentes, temática y estílicamente, como $\mathrm{HHhH}$ de Laurent Binet (2009), o El Reino de Emmanuel Carrère (2015).

11 4- la recopilación de testimonios o grabación de una palabra. Pasando ahora a la vertiente de la grabación, conviene recordar que la literatura, y más generalmente el lenguaje, no puede realmente grabar sino hechos lingüísticos, enunciados ${ }^{5}$. Se puede entonces distinguir dos casos. $\mathrm{O}$ la operación literaria graba y recopila una palabra que acaba de solicitar directamente. Sin añadir nada propio, permite sin embargo el advenimiento de un documento que no existía hasta entonces. O, más mínima aún, se limita a seleccionar, copiar y ensamblar fragmentos de textos preexistentes (montaje de citas y documentos).

12 En cuanto al primer caso (“(4) la recopilación de testimonios”), tomaré como modelos o ejemplos paradigmáticos los libros de Svetlana Alexsievitch acerca de la sociedad 
soviética y post-soviética ${ }^{6}$ y los de Jean Hatzfeld sobre el genocidio de Ruanda (2000, 2003, 2007 y 2015). Lo importante aquí, y que rompe con las categorías anteriores, es que la factualidad de esos textos radica menos en la postura asertiva de sus autores (aunque ésta se afirma indudablemente en los capítulos introductorios, conclusivos o intercalados) que en la confianza en el carácter fidedigno y no engañoso de los procesos de grabación, transcripción y a veces de composición que permiten pasar de la palabra ajena a su inscripción en la hoja. Como en el caso de las grabaciones fílmicas o sonoras, si algo permanece aquí de la aserción, ésta no puede sino ser implícita y formal. El autor queda entonces comprometido, no en cuanto al valor de verdad de lo relatado, claro está, sino en cuanto a su propia honestidad y fidelidad a lo largo del proceso de transcripción. Otra especificidad más, importante en relación con la próxima categoría, es que los actos de habla que se recopilan mediante esos textos fueron directamente solicitados por sus autores, bajo la forma de entrevistas, y que nunca hubiesen ocurrido independientemente del proyecto que implica tal solicitación. Eso significa entonces que el autor es responsable, no sólo de la fidelidad de su transcripción, sino también, anteriormente, de las condiciones de puesta en contacto, de solicitación, de intercambio y de escucha con la persona entrevistada, incluso si esas condiciones no aparecen de forma explícita en el texto.

13 5- el montaje de documentos verbales o el arte de la copia. El mundo habla, mucho, y todo el tiempo, y por miles de razones. Sucede que, por muchísimas razones también, esos actos de habla quedan consignados y transcritos, conservados por escrito. Esa es la materia de mi quinta categoría, en la cual consideraré como figura paradigmática los montajes literarios sacados de archivos judiciales, como Témoignage y Holocauste de Charles Reznikoff (1965 y 1975), Indagación, de Peter Weiss (1968), o más recientemente, Bogoro de Franck Leibovici y Julien Seroussi (2016). La responsabilidad del autor no reside, entonces, en la fidelidad más o menos sólida de una transcripción que no pudo realizar por sí mismo, sino en los desfases, más o menos importantes y significativos, que se permite durante el proceso de edición y de composición del texto. Otra responsabilidad radica en las modalidades de presentación del documento, las cuales no son necesariamente de naturaleza discursiva, sino que pueden adoptar la forma, como lo ilustra Bogoro, de un trabajo en apariencia simple de edición, tipografía e integración de enlaces hipertextuales. Se podría también ampliar la categoría hacia los simples montajes de citas como El corto verano de la anarquíal de Hans Magnus Enzensberger (2006).

14 Trataré de las tres primeras categorías (testimonio en sentido fuerte, testimonio en sentido débil, y relato histórico) en la sección "Testimonio e investigación", y de las dos últimas (compilación de testimonios y montaje de documentos) en la sección "Grabaciones: recopilar una palabra/montar documentos". Pero antes tengo que ocuparme de un punto problemático. En este capítulo dedicado a la literatura, y anteriormente incluso, recurro ampliamente a una definición pragmática de la no ficción en su sentido de acto de compromiso asertivo. En el capítulo dedicado a las imágenes documentales, me era entonces necesario señalar los límites encontrados por el concepto de aserción (que de ninguna manera ha sido forjado para ellas). Ahora bien, dentro del campo literario, parece que, una vez puesto de lado el caso específico de las grabaciones o transcripciones, el modelo asertivo puede funcionar plenamente. No obstante, la formulación inicial de este modelo por Searle venía acompañada de una tesis lateral, y sin embargo radical, que defendía el carácter exclusivamente pragmático del intercambio entre ficción y no ficción, o sea, la ausencia de cualquier determinación 
o propiedad interna a los textos capaz de avalar un diagnóstico de ficcionalidad o no ficcionalidad. El estatuto ficcional o no ficcional de un texto dependería entonces íntegramente de las intenciones y de los actos pragmáticos del sujeto-autor, de su capacidad para comunicar debidamente sus intenciones y sus actos, y de ningún modo dependería de la manera como el propio contenido, desde adentro, se encuentre articulado, presentado y enunciado. Dicho de otro modo, ninguna propiedad sintáctica, semántica o estilística podría permitir por sí sola distinguir entre un texto de ficción y de no ficción. Si se admite tal posición, la totalidad de mi dispositivo, voluntariamente mixto (pragmático y semántico, basado en las intenciones del autor y, al mismo tiempo, en las pruebas epistémicas que concede), colapsa. La idea de "ficcionalidad de los medios", destacada en el capítulo II, ya no tendría sentido, y ya no habría por qué no considerar A sangre fría de Truman Capote como una verdadera obra de no ficción (de hecho, esa parecía ser la intención del autor, fuertemente destacada por el subtítulo del $\mathrm{libro}^{7}, \mathrm{y}$, en cierto modo, esa fue su recepción). Pero entonces, por ósmosis o rebote, sería el mismo intercambio entre ficción y no ficción lo que se volvería una simple cuestión de grados: al fin y al cabo, entre imaginar un punto de vista ficticio sobre eventos reales e imaginar eventos sin más, el trecho no es tan largo. Este importante reto se relaciona con un debate técnico que los especialistas en poética y narratología llamaron el "problema de los indicios de ficcionalidad". Me toca ahora recordar este debate $\mathrm{y}$, si me es posible, zanjarlo.

\section{BIBLIOGRAFÍA}

Alexievitch, Svetlana, Los muchachos de zinc. Voces soviéticas de la guerra de Afganistan, Barcelona, Debate, 2015 (Les cercueils de zinc, París, Bourgeois, 1991).

---, Voces de Chernóbil. Crónica del futuro, Barcelona, Debate, 2015 (La supplication. Tchernobyl, chronique du monde après l'apocalypse, París, Lattès, 1999).

---, El fin del « Homo Sovieticus », Barcelona, Acantilado, 2015 (La fin de l'homme rouge ou le temps du désenchantement, Arles, Actes Sud, 2013).

Binet, Laurent, HHhH, París, Grasset, 2009.

Bloomfield, Camille y Zenetti, Marie-Jeanne, Usages du document en littérature. Production, appropriation, interprétation, Littérature n¹66, 2012/2, París, Armand Colin/Larousse.

Bouvier, Nicolas, Los caminos del mundo, Madrid, Ediciones Península, 2001 (L'usage du monde, CEuvres, París, Gallimard, 2004, p. 75-387).

Carrère, Emmanuel, De vidas ajenas, traducción de Jaime Zulaika, Barcelona, Anagrama, 2011

(D'autres vies que la mienne, París, Gallimard, 2010).

---, El Reino, Barcelona, Anagrama, 2015 (Le royaume, París, P.O.L, 2014).

Enzensberger, Hans Magnus, El corto verano de la anarquía, Barcelona, Anagrama, 2006 (Le bref été de l'anarchie, París, Gallimard, 1975).

Hatzfeld, Jean, Dans le nu de la vie. Récits des marais rwandais, París, Seuil, 2000. 
---, Une saison de machettes, París, Seuil, 2003.

---, La stratégie des antilopes, París, Seuil, 2007.

---, Englebert des collines, París, Gallimard, 2014.

---, Un papa de sang, París, Gallimard, 2015.

Jeannelle, Jean-Louis, “Littératures factuelles”, Fabula, Web. Consultado el 26 de febrero de 2017.

Leibovici, Franck y Seroussi, Julien, Bogoro, París, Questions théoriques, 2016.

Levi, Primo, Si esto es un hombre, México, Austral, 2013 (Si c'est un homme, París, Julliard, 1987.

Makagasana, Yolande y May, Patrick, La mort ne veut pas de moi, París, Fixot, 1997.

Stott, William, "Part Three : The Documentary Nonfiction of the Thirties", Documentary

Expression and Thirties America, Nueva York, Prensa Universitaria de Oxford, p. 141-257.

Reznikoff, Charles, Témoignages. Les États-Unis (1885-1890), París, P.O.L, 2012.

---, Holocauste, París, Editora Unes, 2017.

Rolin, Jean, La cerca, (La Clôture, París, P.O.L, 2002).

Ruffel, Lionel, “Un réalisme contemporain : les narrations documentaires”, Littérature n¹66, 2012/2, París, Armand Colin/Larousse, p. 13-25.

Toker, Leona, Toward a Poetics of Documentary Prose - from the Perspective of the Gulag Testimonies”, Poetics Today vol. 8, n², verano 1997, p. 187-222.

Weiss, Peter, La indagación, Barcelona, Grijalbo, 1968 (L'instruction, París, L’Arche, 2000).

Zenetti, Marie-Jeanne, "Prélèvement/déplacement : le document au lieu de l'œuvre", Littérature $n^{\circ} 166,2012 / 2$, París, Armand Colin/Larousse.

---, Factographies. L'enregistrement littéraire à l'époque contemporaine, París, Classique Garnier, 2014.

\section{NOTAS}

1. Generalización abusiva, en la medida en que Genette no aplicaba el término "factual" sino a los relatos y evitaba hablar de "literatura factual" en general. Ver capítulo "Factualidad y empirismo" del presente libro.

2. Traducción al francés del autor, traducción nuestra al español. [N.T.].

3. A este respecto, habría que mencionar también el importante artículo de Toker, "Toward a Poetic of Documentary Prose -from the Perspective of the Gulag Testimonies" (1997) que, aunque trabaja con un corpus relativamente reducido tiene la ventaja, desde mi punto de vista, focalizándose en testimonios, de no limitar la idea de "literatura documental" a la exclusividad del criterio de la presencia de "documentos" en el texto. Para un análisis detallado de las posiciones de Leona Toker, consultar Zenetti (2014: 78-82).

4. Acerca de la figura de Yolande Mukagasana, ver capítulo "El testigo: Yolande Moukagasana, Dorothée Munyaneza, Rimini Protokoll y Milo Rau".

5. Aquí me alejo de M.-J. Zenetti que, con la noción de "notation", integra dentro de la idea de "grabación literaria" un fenómeno que, de hecho, me parece que alude más bien a la noción de testimonio. 
6. Entre las obras más famosas de S. Alexsievitch, podemos citar Los muchachos de zinc. Voces soviéticas de la guerra de Afganistán (2016), Voces de Chernobil. Cronica del futuro (2015), El fin del «Homo Sovieticus» (2015).

7. "A True Account of a Multiple Murder and its Consequences" ("Un relato real de un asesinato múltiple $y$ sus consecuencias").

\section{AUTORES}

\section{FRÉDÉRIC POUILLAUDE}

Universidad de Aix-Marsella 